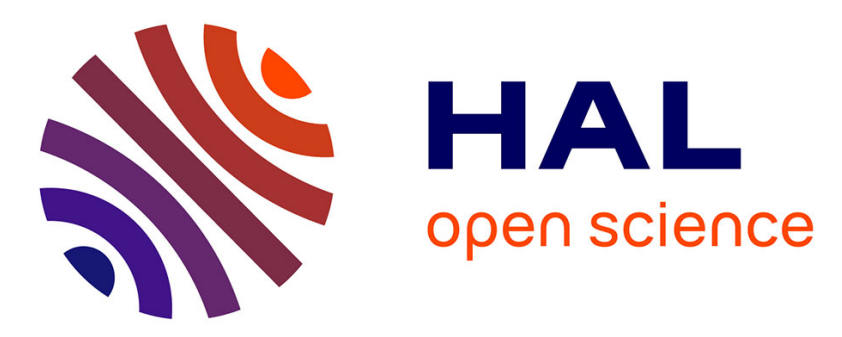

\title{
Identification of the hardening law of materials with spherical indentation using the average representative strain for several penetration depths
}

Charbel Moussa, Xavier Hernot, Olivier Bartier, Guillaume Delattre, Gerard Mauvoisin

\section{To cite this version:}

Charbel Moussa, Xavier Hernot, Olivier Bartier, Guillaume Delattre, Gerard Mauvoisin. Identification of the hardening law of materials with spherical indentation using the average representative strain for several penetration depths. Materials Science and Engineering: A, 2014, 606, pp.409-416. 10.1016/j.msea.2014.03.123 . hal-01003216

\section{HAL Id: hal-01003216 https://hal-univ-rennes1.archives-ouvertes.fr/hal-01003216}

Submitted on 10 Jun 2014

HAL is a multi-disciplinary open access archive for the deposit and dissemination of scientific research documents, whether they are published or not. The documents may come from teaching and research institutions in France or abroad, or from public or private research centers.
L'archive ouverte pluridisciplinaire HAL, est destinée au dépôt et à la diffusion de documents scientifiques de niveau recherche, publiés ou non, émanant des établissements d'enseignement et de recherche français ou étrangers, des laboratoires publics ou privés. 


\title{
Identification of the hardening law of materials with
}

\author{
spherical indentation using the average
}

\section{representative strain for several penetration depths}

\author{
Charbel Moussa* ${ }^{1}$, Xavier Hernot ${ }^{1,2}$, Olivier Bartier ${ }^{1,2}$, Guillaume \\ Delattre $^{3}$, Gérard Mauvoisin ${ }^{1,2}$
}

1 LGCGM EA3913, Université de Rennes1-INSA de Rennes, 20 Avenue des Buttes de Coësmes, 35708 Rennes Cedex 7, France

2 IUT de Rennes 1, 3 rue du Clos Courtel, 35704 Rennes Cedex, France.

3 Faurecia Automotive Seating, Le Pont de Vère, 61100 Caligny, France

Corresponding author: Charbel Moussa, Tel: +33 223232031 E-mail address:

charbel.moussa@univ-rennes1.fr.

\begin{abstract}
:
The identification of plastic properties with spherical indentation has been the subject of many studies in last decades. In the present work, a new method for the determination of the hardening law of materials using the load-displacement curve of a spherical indentation test is proposed. This method is based on the use of an average representative strain. The advantage of the proposed average representative strain is that it is strictly obtained from the material response to the indentation test. By using various values of penetration depth, the proposed method gives the range of strain for which the hardening law is precisely identified and allows determining a confidence domain that takes into account experimental imprecision and material heterogeneity. The influence of penetration depth and the error formula on the identified Hollomon hardening law are discussed in the present study. The present study clarifies many problems that were observed in previous studies such as the uniqueness of solution and the sensitivity of the indentation test to the plastic parameters of the Hollomon hardening law.
\end{abstract}


Keywords: Steel alloy, spherical indentation, hardening law, average representative strain, confidence domain

\section{1- Introduction}

Knowledge of the hardening law is fundamental in design and forming of metal products. This mechanical property is commonly obtained from tensile test. For cases such as plastically and functionally graded materials, biomedical materials, welded components and thin films, the tensile test cannot be applied. The instrumented indentation test is an excellent substitute in such cases for the standard tensile test [1-9] . Identification of plastic hardening parameters from a load-penetration depth spherical indentation curve ( $F$ - $h$ curve) is mostly used and the methods based on the representative strain and stress approach are widely proposed [10-20].

Several methods consist to directly correlate the representative stress and strain to the stressstrain point in the uniaxial tensile test $[10,13-15]$. Other methods consist to determine the parameters of the Hollomon hardening law from a closed-form expression of the $F$ - $h$ curve as a function of material properties $[11,12,16-18,20,21]$. For the second group of methods, the full stress-strain response is commonly estimated from the following piecewise power law assumption:

$$
\left\{\begin{array}{ccc}
\sigma=E \varepsilon & \text { if } & \sigma \leq \sigma_{y} \\
\sigma=E^{n} \sigma_{y}^{(1-n)} \varepsilon^{n} & \text { if } & \sigma \geq \sigma_{y}
\end{array}\right.
$$

Where $\sigma_{y}$ is the yield stress, $n$ is the work hardening exponent and $E$ is the Young's modulus. While the framework for determining the hardening law of materials by considering the $F-h$ curve has been demonstrated to work well for metals, issues of uniqueness [17,22,23] and sensitivity [23-25] have also been identified. Moreover, none of the studies concerning the mechanical characterization using the $F$ - $h$ curve $[11,12,16-18,20,21]$ gave a clear answer on 
the range of strain for which the hardening law is precisely identified. In some studies, no physical justification was given to explain the reason why the proposed strain can be considered as representative of spherical indentation $[10,16]$. In other studies, the use of the representative strain serves as a mathematical trick having no physical basis $[11,12,18,20,21]$. In a recent study[26], an investigation of the domain in which the solution exists while identifying the hardening law of a material with spherical indentation using the $F-h$ curve was performed. A definition of an average representative strain only based on the material response to the indentation test, i.e. the $F-h$ curve, was also proposed in this study. Based on the use of this average representative strain, a new identification method that allows identifying the hardening law of materials for a well-known range of strain is proposed in the present study. Also, the influence of the penetration depth and the choice of the error formula used in the identification process is investigated and overtaken in the proposed method.

\section{2-Material presentation and experimental results}

The studied material denoted 20MnB5 steel (European Standard EN 10083-3, Steelgrade number: 1.5530) is a commercial Hot-rolled boron-alloyed case-hardening and heat-treatable steel, provided by Hoesch Hohenlimburg GmbH. The chemical composition in weight is: $0.191 \% \mathrm{C}, 1.14 \% \mathrm{Mn}, 0.362 \% \mathrm{Si}, 0.0158 \% \mathrm{P}, 0.0008 \% \mathrm{~S}, 0.25 \% \mathrm{Cr}, 0.0014 \% \mathrm{~B}, 0.039 \% \mathrm{Al}$, $0.027 \% \mathrm{Ti}, 0.017 \% \mathrm{Mo}, 0.025 \% \mathrm{Cu}$ and $0.06 \% \mathrm{Ni}$. The steel has been hot rolled to a thickness of $4.5 \mathrm{~mm}$. All investigations have been performed on the material in this as received condition.

The micrograph in Fig. 1 shows, as a result of the hot rolling, a fine and homogeneous distribution of spheroidized carbides in a ferritic matrix. This microstructure gives excellent properties in the as rolled condition for cold forming, slitting and machining without additional annealing processes. For our study, this type of steel was selected because of this 
fine, homogeneous microstructure, which leads to a good reproducibility of the indentation tests.

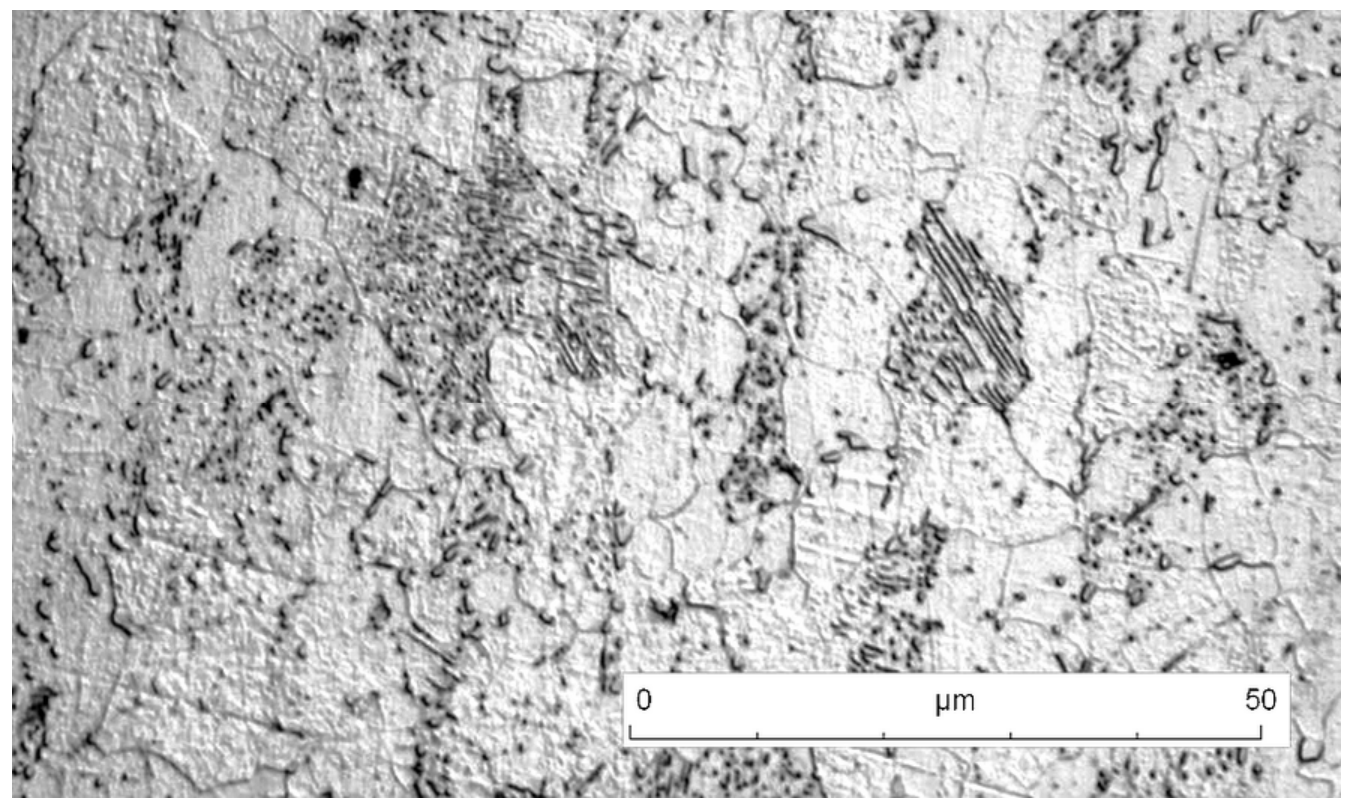

Fig. 1: Microstructure of the 20MnB5 steel alloy

The tensile test and indentation specimens were carefully sectioned with a Precision Cut-Off Machine from the hot rolled sheet. The Vickers hardness (10Kgf) measurements gave: $\mathrm{HV}_{10}=155$ for the surface and $\mathrm{HV}_{10}=160$ for the core. The true tensile curves obtained for 20MnB5 steel before necking are represented in Fig. 2. The experimental conditions and measurement method for the tensile test were presented in a previous study [6]. Fig. 2 shows that the studied material exhibits a yield stress of about $340 \mathrm{MPa}$ and a non-negligible work hardening. This figure also shows that the Hollomon equation does not describe the entire flow curve for the 20MnB5 steels 


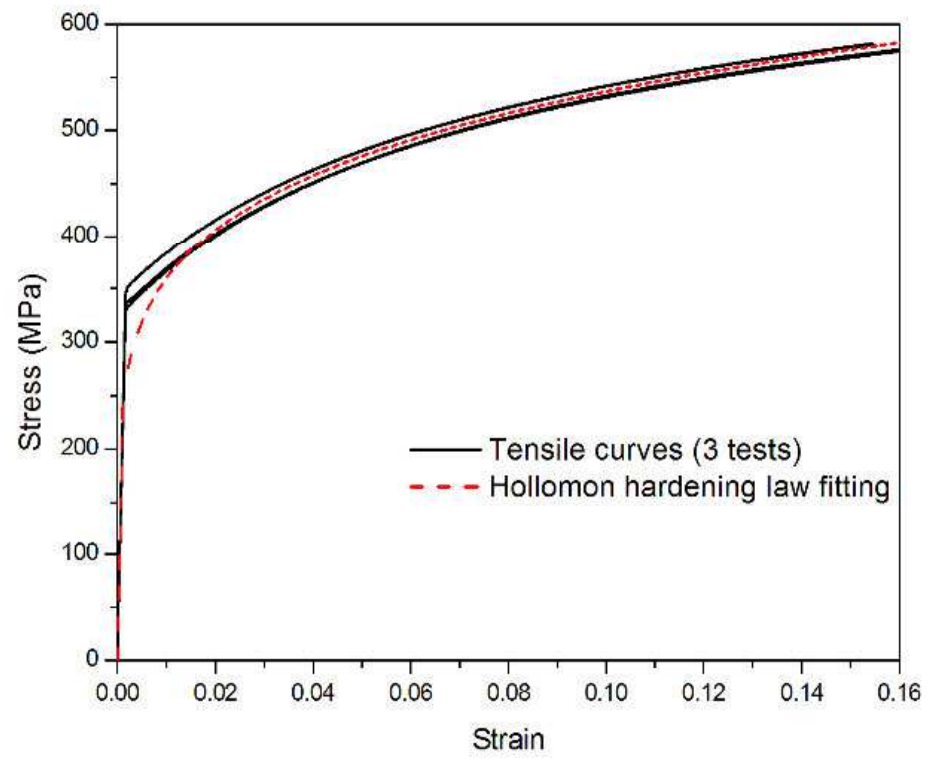

Fig.2: Uniaxial tensile test curves for 20MnB5 steel alloy [26]

The spherical indentation tests were carried out with a tungsten carbide ball of radius $0.5 \mathrm{~mm}$. The indentation bench and the experimental conditions used for the indentation tests were detailed in a previous study [6]. Four spherical indentation curves were obtained from the material. Fig. 3 shows that a satisfying reproducibility of the indentation tests was obtained.

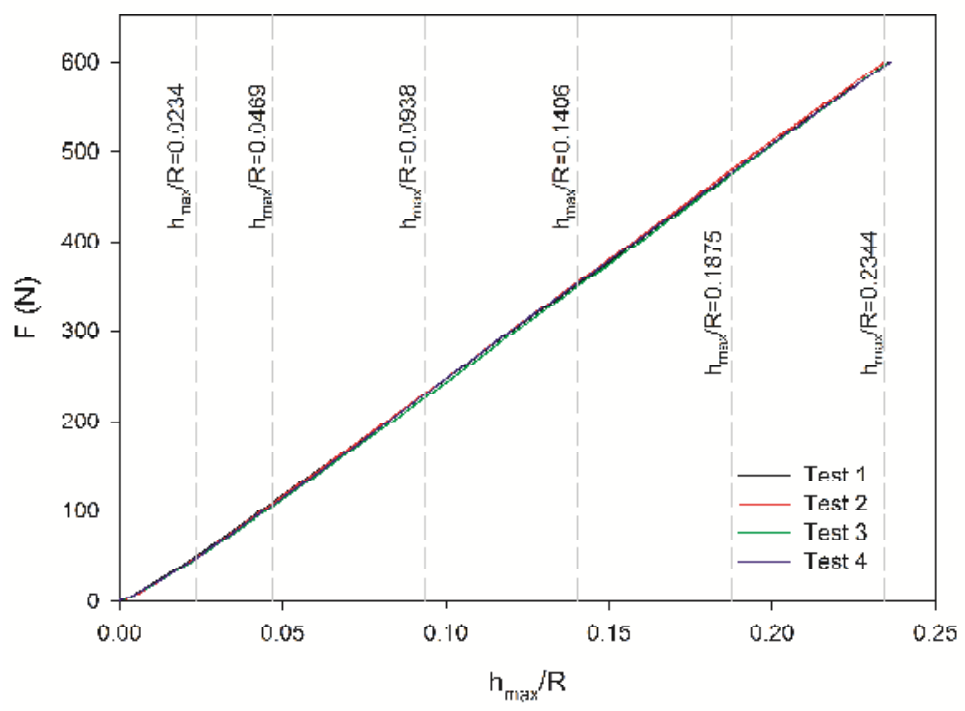

Fig. 3: Spherical indentation curves for $20 \mathrm{MnB5}$ steel alloy 


\section{2- Evaluation of the tensile properties from one value of $h_{\max } / R$}

\section{ratio}

Using the four experimental indentation curves (see fig.3), the average curve is determined (average load for every penetration depth). In the present study, only the average curve is used to characterize the material. In order to quantify the gap between two indentation curves, the root mean square error, equation 2, was used:

$$
E_{R M S}\left(h_{\max } / R\right)=\sqrt{\frac{1}{h_{\max }} \int_{0}^{h_{\max }}\left(F_{1}-F_{2}\right)^{2} d h}
$$

Where $R$ is the spherical indenter radius $(0.5 \mathrm{~mm}), h$ is the penetration depth, $h_{\max }$ is the maximal penetration depth and $F_{1}$ and $F_{2}$ are the load for the two considered curves. In this section one penetration depth is treated $\left(h_{\max } / R=0.2344\right)$. The characterization procedure consists to calculate the gap, using $E_{R M S}$ (Eq. (2)), between an experimental $F$ - $h$ curve and a number of $F$ - $h$ curves obtained from Finite Element simulations for different Hollomon hardening law parameters. The finite elements (FE) model was presented in a previous study [26]. The elastic properties of the simulated materials correspond to the elastic properties of the steels, i.e.: $E=210 \mathrm{GPa}$ and $v=0.3$. A database was built up from $F$ - $h$ curves obtained from finite element simulations of the spherical indentation test with different combinations of plastic properties presented in Fig.4a. 


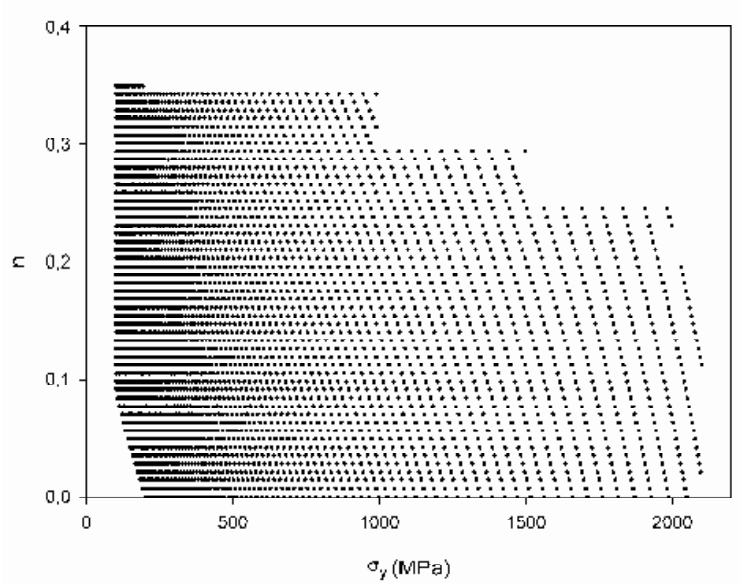

(a)

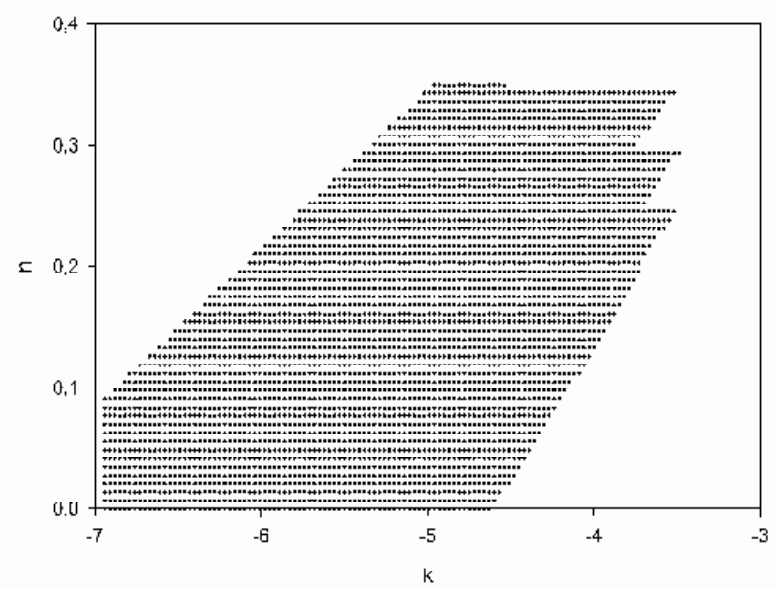

(b)

Fig.4: (a) Materials Plastic properties used for the database in $\left[\sigma_{y}, n\right](b)$ and in $[k, n]$

\section{diagram}

The $E_{R M S}$ distribution in $\left[\sigma_{y}, n\right]$ diagram is presented in Fig.5. As presented in the previous study [26], the $E_{R M S}$ distribution takes a particular form of a cone with an elliptical base in the $[k, n]$ diagram, where $k$ is defined as follow:

$k=(1-n) \ln \left(\frac{\sigma_{y}}{E}\right)$

Since the $E_{R M S}$ distribution form (cone with an elliptical base) is known in $[k, n]$ diagram, the values of the hardening law parameter sets of the database were chosen to be regular in $[k, n]$ diagram (fig.4b). 

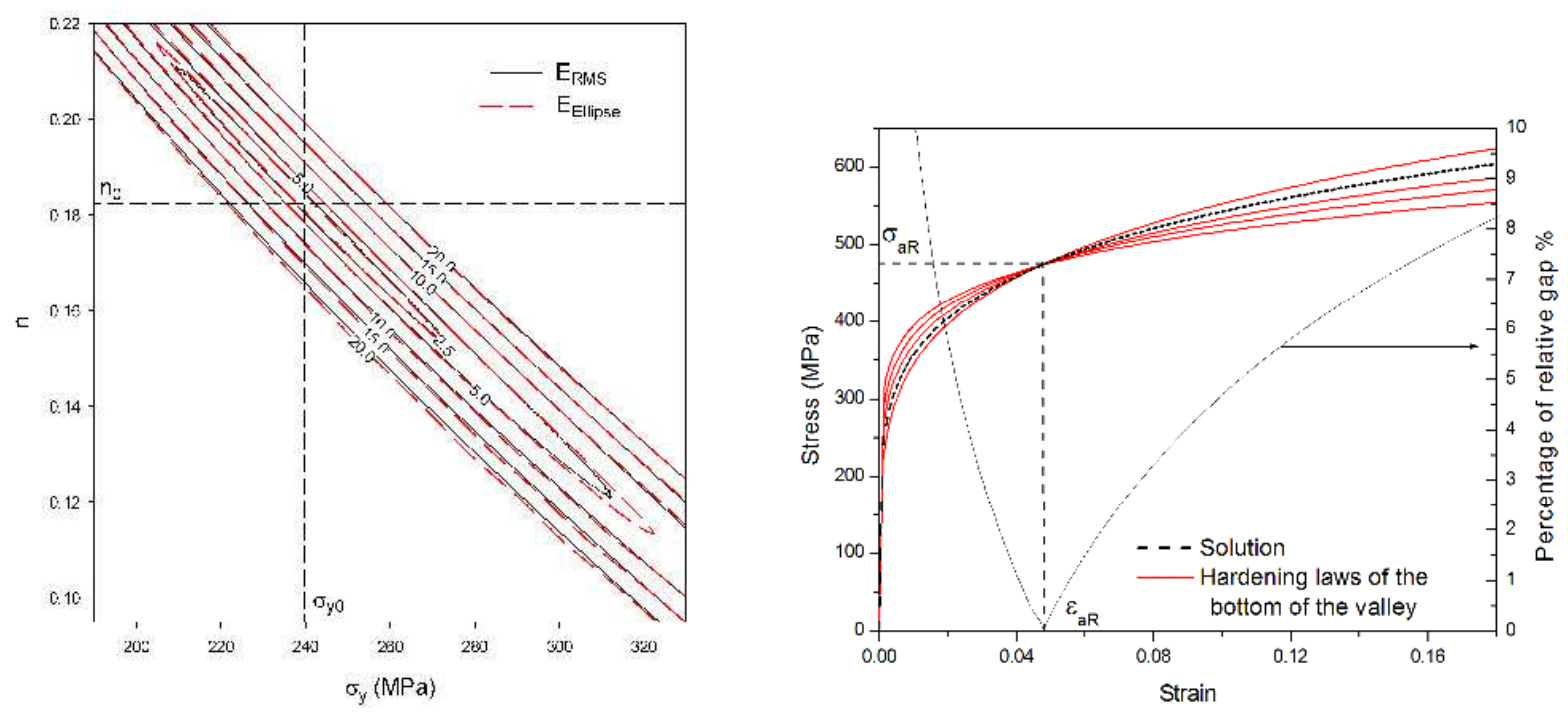

Fig.5: (a) Comparison between the ERMS distributions obtained from the database and the cone with the elliptical base [26]

(b) Hardening law of the materials for which the material parameter sets $\left(\sigma_{y}, n\right)$ are located in the bottom of the valley (see Fig.5 (a)) and percentage of the maximal relative gap between these curves[26]

The mathematical equation of this cone, used to determine the Hollomon hardening law of the material, is:

$$
E_{\text {ellipse }}=\sqrt{\left(\frac{x}{X}\right)^{2}+\left(\frac{y}{Y}\right)^{2}}
$$

with

$$
x=\left(k-k_{0}\right) \cos \theta_{a R}+\left(n-n_{0}\right) \sin \theta_{a R}
$$

and

$$
y=-\left(k-k_{0}\right) \sin \theta_{a R}+\left(n-n_{0}\right) \cos \theta_{a R}
$$


where $X$ and $Y$ are the parameters that indicates the dimensions of the elliptical base for one specific value of error. The dimensional unit of $X$ and $Y$ is the inverse of the dimensional unit of $E_{\text {ellipse. }} K_{0}$ and $n_{0}$ are the coordinates of the summit of the cone, i.e. the identified solution and $\theta_{a R}$ indicates the direction of the principal axis of the ellipse in $[k, n]$ diagram.

The units of $E_{\text {ellipse }}$ and $E_{R M S}$ are identical (Newton, in our case).

The comparison between $E_{R M S}$, obtained from the database, and $E_{\text {ellipse }}$ obtained from Eq. (4) is presented in Fig.5a. In Fig.5a, it is clearly shown that the $E_{\text {ellipse }}$ distribution given by Eq. (4) superimposes perfectly onto the $E_{R M S}$ distribution. This result proves that the considered assumption on the cone with the elliptical base form is correct.

From Fig.5a, we can notice the presence of a "valley" in the $\left[\sigma_{y}, n\right]$ diagram in which the $E_{R M S}$ variation is very small. All the $\left(\sigma_{y}, n\right)$ parameters that are located in the bottom of this valley lead to hardening laws that intersect at one specific strain (Fig.5b). This strain, which depends on the direction of the valley, was defined as the average representative strain, $\varepsilon_{a R}$ [26]. All the $\left(\sigma_{y}, n\right)$ parameters which are located in the bottom of the valley lead to $F$ - $h$ curves close to the $F$ - $h$ curve corresponding to the solution. Hence, the $F$ - $h$ curve is mostly influenced by the part of the hardening law which is located around the average representative strain, $\varepsilon_{a R}$. When a material is characterized using the $F-h$ curve, it is this part of the Hollomon hardening law that is mostly characterized and the better identified. To determine $\varepsilon_{a R}$ the following equation is used [26]:

$$
\varepsilon_{a r}=\exp \left(\frac{-1}{\tan \theta_{a r}}\right)
$$

The 5 parameters, $X, Y, n_{0}, \sigma_{y 0}$ and $\theta_{a R}$, are obtained from the minimal value of the following cost function:

$$
E=\sum\left(E_{\text {RMS }}^{i}-E_{\text {ellipse }}^{i}\right)^{2} \text { with } E_{\text {RMS }}^{i}-E_{\text {ellipse }}^{i}=0 \quad \text { if } \quad E^{i}{ }_{R M S} \geq E_{\text {critical }}
$$


where $i$ corresponds to each case of the material parameter sets $\left(\sigma_{y}, n\right)$ that were chosen for the database. It should be noticed that the elliptical cone form was assumed to be the form of the $E_{R M S}$ distribution near the solution, i.e where the valley exists. For this reason, $E_{\text {critical }}$ was defined in order to use only the material parameter sets that are near the solution to correctly determine the five parameters of the elliptical cone. In this study $E_{\text {critical }}=30 \mathrm{~N}$ was chosen for $h_{\max } / R=0.2344$. In the case of $h_{\max } / R=0.2344$, the parameters of the identified hardening law, presented in Fig.6, are: $\sigma_{y}=240 \mathrm{MPa}$ and $n=0.182$. The comparison between the identified hardening law and the tensile test curves shows that the identified parameters of the hardening law give a stress strain curve very close to the experimental tensile test curves.

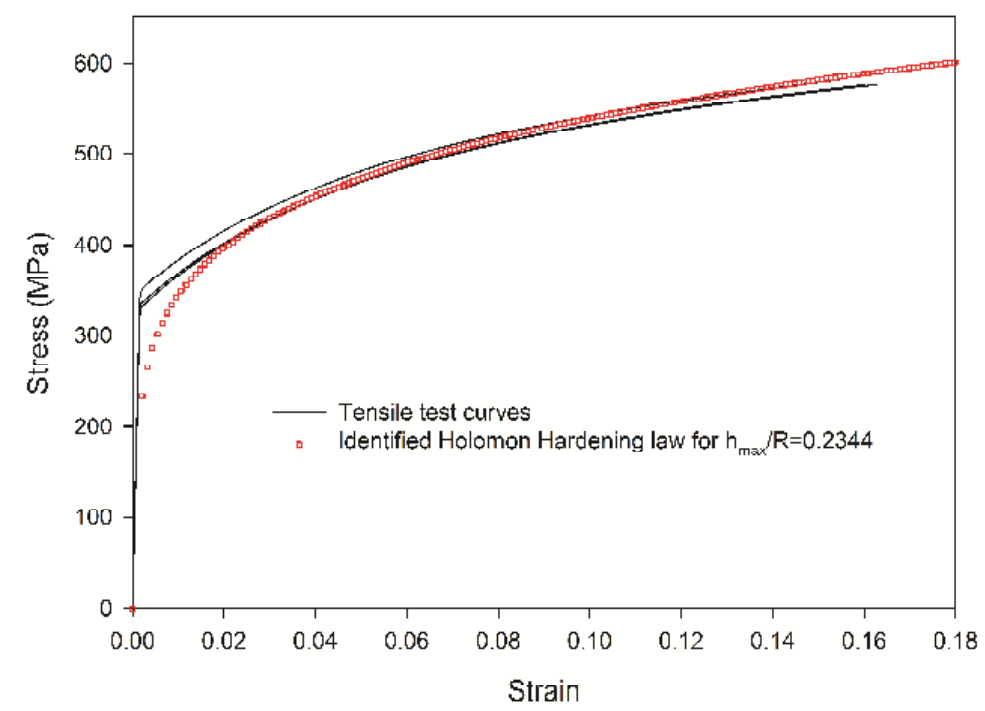

Fig.6: Comparison between the tensile test curves and the identified hardening law with the elliptical cone definition.

Furthermore, the proposed identification method [26]allows identifying a confidence domain. When multiple experimental indentation curves are used, differences between these curves are always observed. One cannot obtain two experimental curves that superimpose perfectly because of the experimental imprecision and the material heterogeneity. 
In order to quantify those differences, $E_{R M S}$ is calculated between the average experimental $F$ $h$ curve and each one of the four experimental curves for a $h_{\max } / R=0.2344$.

$E_{R M S}(\mathbf{N})$

\begin{tabular}{llllll}
\hline \hline $\boldsymbol{h}_{\max } / \boldsymbol{R}$ & Test 1 & Test 2 & Test 3 & Test 4 & Maximum \\
\hline 0.2344 & 1.17 & 1.97 & 2.50 & 0.85 & 2.50
\end{tabular}

Table 1: Values of root mean square error $\left(E_{R M S}\right)$ between the average curve and the four experimental curves [26]

The values of $E_{R M S}$ obtained between the average curve and the four experimental curves are presented in table 1. Using the equation of the cone with the elliptical base (Eq. (4)), the ellipse which corresponds to the maximum value of $E_{R M S}$ given in Table 1 is determined. This ellipse (isovalue of $E_{R M S}$ ) is presented in $\left[\sigma_{y}, n\right]$ and $[K, n]$ diagrams (Fig.7a). All the Hollomon hardening laws parameters that are located inside this ellipse can be considered as solutions. We define the confidence domain (in stress-strain diagram) as the envelope of these hardening laws [26]. The confidence domain, that delimits the hardening laws identified as solutions, is presented in Fig.7b.
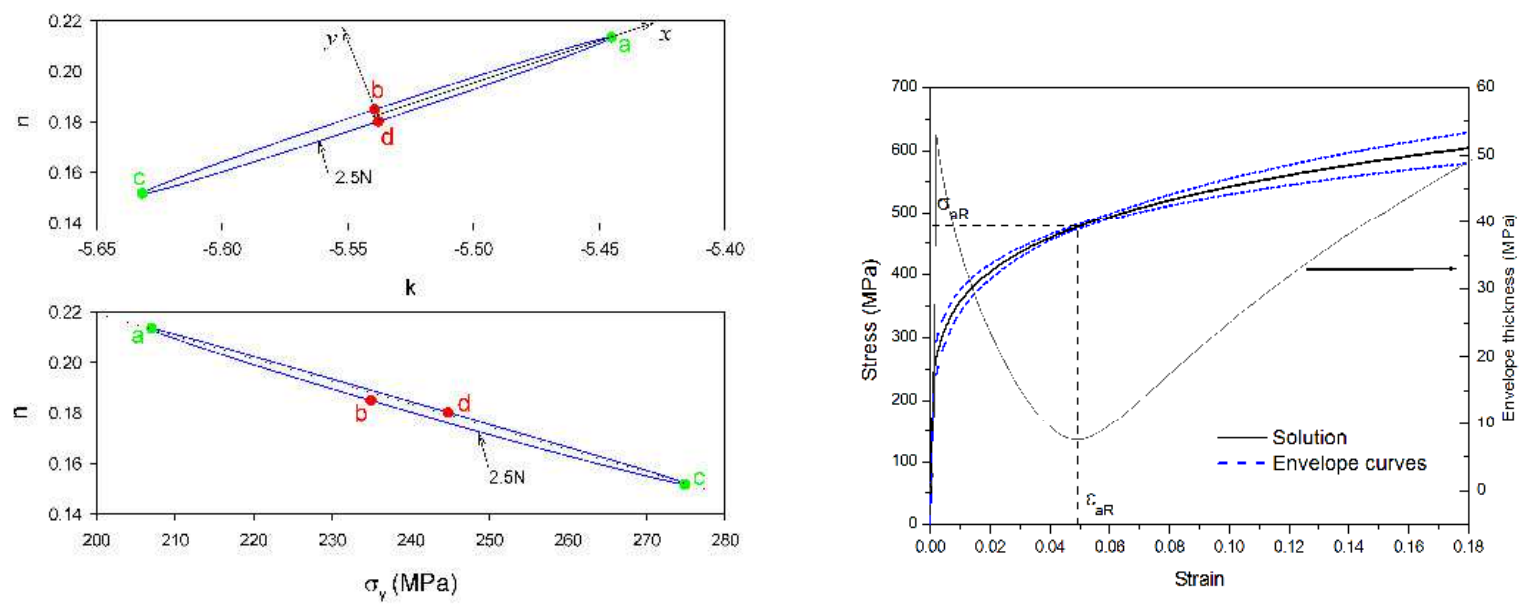

(a)

(b) 
Fig.7: (a) Ellipse corresponding to the maximal value of ERMS between the experimental curves (table 1) [26].

(b) Identified solution and confidence domain limited with the envelope [26].

In this section, an identification method that allows identifying the Hollomon hardening law parameter set $\left(\sigma_{y}, n\right)$ and the average representative strain was proposed for one specific penetration depth $\left(h_{\max } / R=0.2344\right.$ was used). As described above the average representative strain indicates the part of the Hollomon hardening law that is identified with the highest precision. In order to identify the hardening law of the material with the highest precision, the same procedure is applied for multiple penetration depth in the following section.

\section{3- Evaluation of the tensile properties from multiple $h_{\max } / \boldsymbol{R}$}

\section{1- Influence of penetration depth on the identified hardening law}

As for the previous section, the average experimental indentation curve obtained for the 20MnB5 steel is used. Using the definition of the cone with the elliptical base (Eq. (4), (8)), the Hollomon hardening law parameter sets $\left(\sigma_{y}, n\right)$ are calculated for various values of $h_{\max } / R$ $\left(0.0055<h_{\max } / R<0.2344\right)$. Fig. 8 shows that the maximum penetration depth has a strong influence on the values of the identified parameters of the studied material. Furthermore, a correlation between $\sigma_{y}$ and $n$ is observed. $\sigma_{y}$ decreases and $n$ increases when $h_{\text {max }} / R$ increases. From these observations, it becomes difficult to make a choice of $h_{\max } / R$ to characterize a material with a Hollomon hardening law. A question is to be asked: which set of parameters should be considered as solution? 


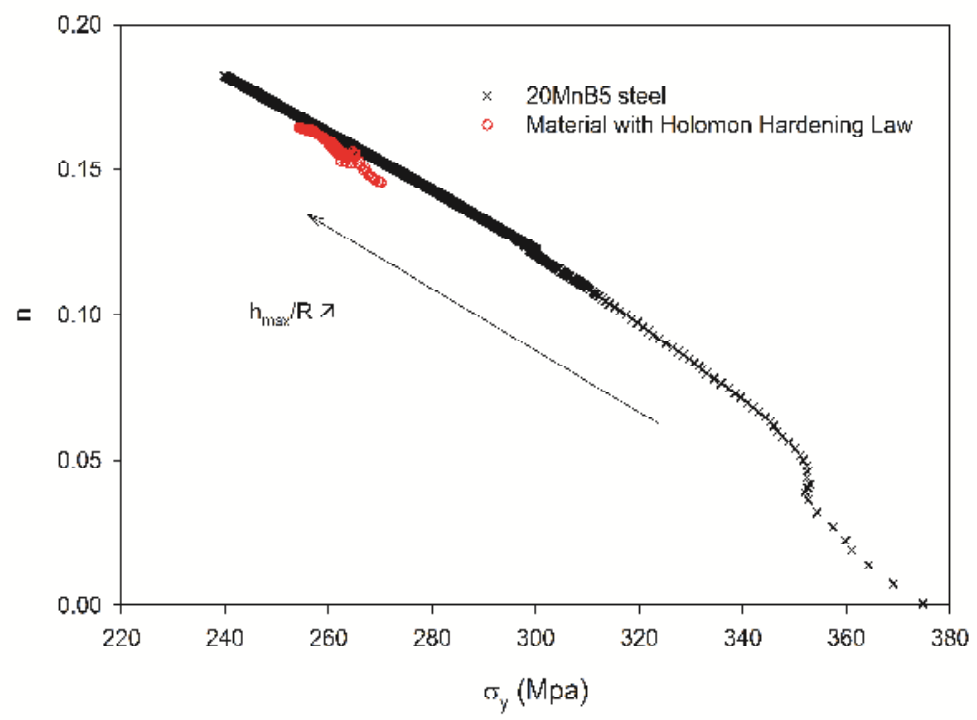

Fig.8: Material parameter sets $\left(\sigma_{y}, n\right)$ identified with spherical indentation for different penetration depth $\left(0.0055<h_{\max } / R<0.2344\right)$ for the case of $20 \mathrm{MnB5}$ steel alloy (experimental result) and the case of a material with $\sigma_{y}=260 \mathrm{MPa}$ and $n=0.16$ (FE simulation result)

\section{Discussion}

The results presented in black color in Fig. 8 were obtained for the 20MnB5 steel for which the hardening law does not correspond perfectly to a Hollomon law. We propose to study the influence of the penetration depth on the identified hardening law for a material with a Hollomon hardening law. The $F-h$ curve was obtained from FE simulation for a material with $\sigma_{y}=260 \mathrm{MPa}$ and $n=0.16$. From this indentation curve and using the definition of the cone with the elliptical base (Eq. (4), (8)), the Hollomon hardening law parameter sets $\left(\sigma_{y}, n\right)$ are calculated.

From Fig.8, it can be observed that the values of the identified Hollomon hardening law parameters are almost identical for every value of $h_{\max } / R$. The small variations of the values of $\sigma_{y}$ and $n$ observed in Fig. 8 are only due to the precision of the minimization process in the proposed method (Eq. (8)). Hence, when the hardening law of the material corresponds 
perfectly to a Hollomon law, there is no influence of the penetration depth on the identified parameter set $\left(\sigma_{y}, n\right)$. On the other hand, when the hardening law of the material does not correspond perfectly to a Hollomon law, the identified parameter set $\left(\sigma_{y}, n\right)$ depends on the penetration depth (Fig.8). From this result the problem of the uniqueness of solution in spherical indentation should be investigated.

Methods for the identification of the Hollomon parameter set $\left(\sigma_{y}, n\right)$ from spherical indentation curve, $F$ - $h$, were proposed in many studies [11,12,16-18,20-22]. In each study, one value of maximum penetration depth was chosen and was considered as sufficient to characterize the studied materials. No clear explanation on the choice of this value was given. For example, Lee et al [16] proposed a model for the identification of the Hollomon hardening law parameter sets $\left(\sigma_{y}, n\right)$. They chose a maximal ratio $h_{\max } / R=0.12$ with no justification. Later, in 2010, Lee et al. [17] showed that there could be a problem of uniqueness of solution for $h_{\max } / R=0.12$. They showed that two dissimilar materials may produce quite similar $F$ - $h$ curves for shallow indentation, i.e. $h_{\max } / R=0.12$. They also showed that as indentation depth increases, the $F$ - $h$ curves clearly separate from each other. This features inspired the authors [17] to develop a modified method for a deeper spherical indentation test, i.e. $h_{\max } / R=0.4$. The reason why this choice would definitely solve the problem of uniqueness of the solution was not given.

We show that the value of the identified parameter set $\left(\sigma_{y}, n\right)$ is about the same independently of the value of $h_{\max } / R$ in the case of a material with a hardening law which corresponds perfectly to a Hollomon law (Fig.8). In the case of a material with a hardening law which does not correspond to a Hollomon law, Fig. 8 shows that the values of the identified parameter set $\left(\sigma_{y}, n\right)$ depend on the value of $h_{\max } / R$. In the following part, a procedure of characterization which takes into account the values of the identified parameter sets $\left(\sigma_{y}, n\right)$ obtained for all values of $h_{\max } / R$ is proposed. 


\section{2- Identification using the average representative strain}

In section 2 the average representative strain was only used to give additional information on the part of the hardening law that is identified with the highest precision. In this section the average representative strain is used to build the hardening law of the material point by point. Using Eq. (4), (7) and (8), a material parameter set $\left(\sigma_{y}, n\right)$ and an average representative strain $\varepsilon_{a r}$ are determined for each value of $h_{\max } / R$. Using the fact that the higher the $h_{\max } / R$ ratio the higher $\varepsilon_{a r}$ is, various set $\left(\varepsilon_{a r}, \sigma_{a r}\right)$ are determined for various $h_{m a x} / R$. This way, the hardening law of the material is built up with different sets $\left(\varepsilon_{a r}, \sigma_{a r}\right)$. Fig.9 shows that the built up hardening law is very close to the tensile test curves of the material.

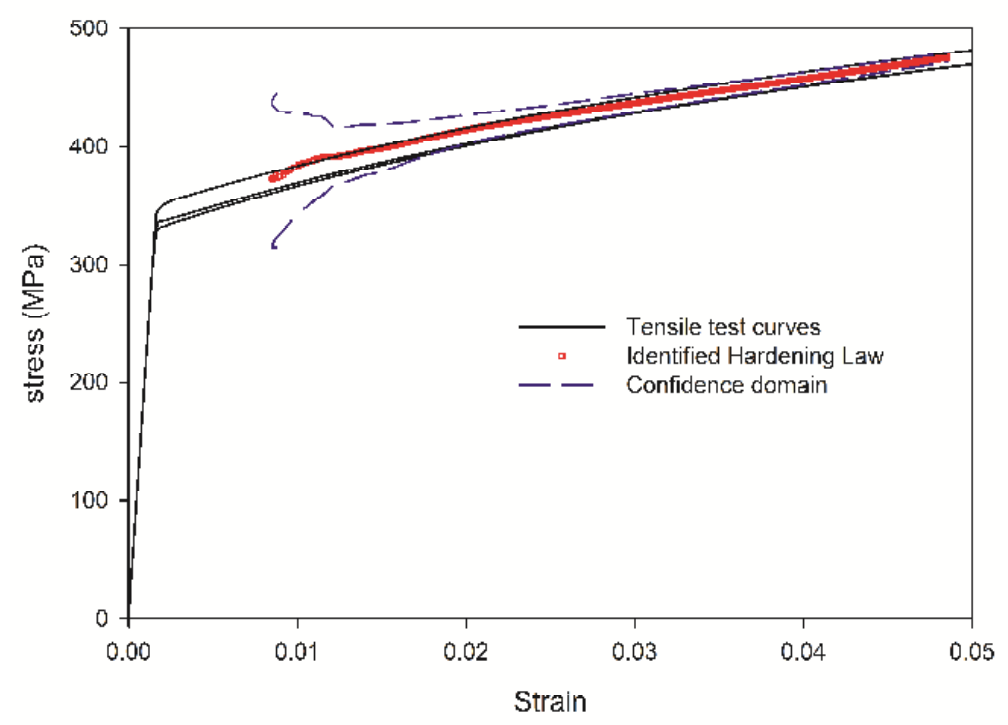

Fig.9: Tensile test curves, hardening law identified with the proposed method and confidence domain determined with the proposed method.

\section{Discussion}

In the paragraph 3.1 the question of uniqueness of solution was invoked for the case of 20MnB5 steel. We show in Fig.8 that different Hollomon hardening law parameter sets $\left(\sigma_{y}, n\right)$ 
are identified depending on the value of $h_{\max } / R$. There is no reason to choose one specific material parameter set $\left(\sigma_{y}, n\right)$ among the identified ones. The Hollomon hardening laws, obtained from parameter sets $\left(\sigma_{y}, n\right)$ identified for small values of $h_{m a x} / R$, better represent the beginning of the plastic flow of the material. In a similar way, the Hollomon hardening laws, obtained from parameter sets $\left(\sigma_{y}, n\right)$ identified for high values of $h_{\max } / R$, better represent the plastic flow of the material for high values of strain. The procedure presented in this study allows considering all the identified Hollomon hardening laws obtained from small to large values of $h_{\max } / R$. For each one of these laws, the corresponding point $\left(\varepsilon_{a r} \sigma_{a r}\right)$ is considered because it is for this point that the result is the most precise when using the $F$ - $h$ curve for the identification of the hardening law. Using the built up hardening law with the various $\left(\varepsilon_{a r}\right.$ $\left.\sigma_{a r}\right)$, no value of $h_{\max } / R$ ratio is considered more important than the others. With the proposed method, all $h_{\max } / R$ between 0.0055 and 0.2344 are equally considered and no unjustified choice was made on the value of the used $h_{\max } / R$ for the identification of the hardening law of the material. Even more, the range of plastic strains, for which the hardening is identified, is directly obtained, i.e between 0.012 and 0.049 for the studied case. The proposed method is similar to the methods $[10,13,15,19,27]$ based on the measure of applied load and contact radius from which the hardening law is built up point per point. The advantage of the proposed method is that the average representative strain is directly determined from measured parameters $(F$ and $h)$, which is not the case for the methods cited above. In these methods, the representative strain is obtained from the value of contact radius which is calculated from the value of penetration depth using models. In the studies on the representative strain in spherical and Vickers indentations, it was shown that the values of representative strain obtained from the $F$ - $h$ relationship are smaller than those obtained from the $F$ - $a$ relationship [28]. The use of the $F$ - $a$ relationship in addition to the $F$ - $h$ relationship must thus lead to the identification of complementary parts of the hardening law of a material. 


\section{3- Confidence domain}

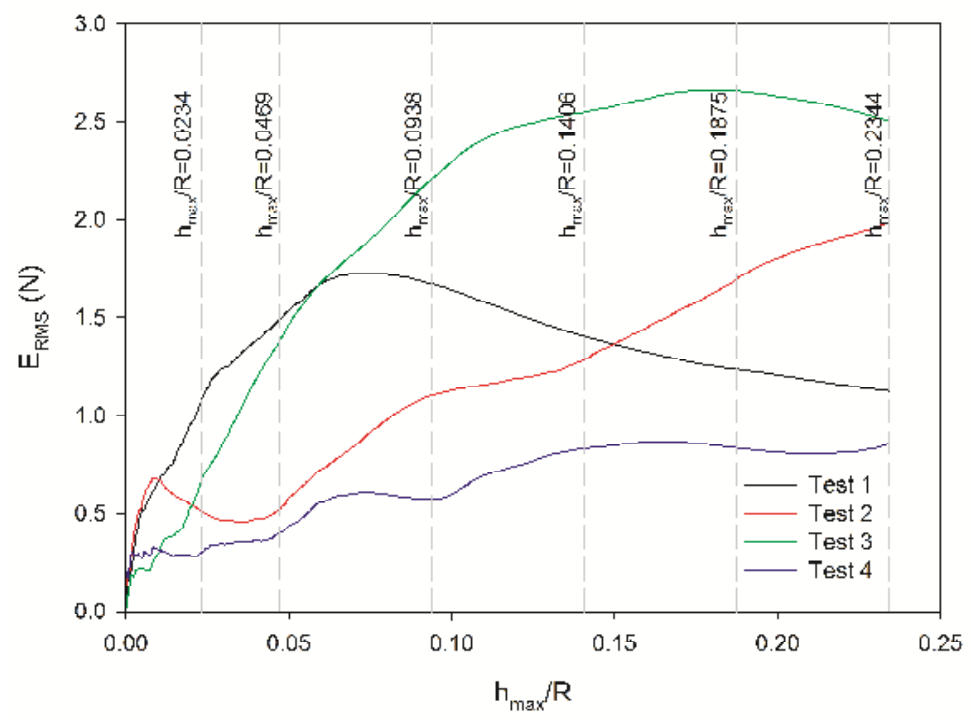

Fig.10: Evolution of the error between the average curve and the four indentation curves as a function of the ratio penetration depth over indenter radius

In order to take into account experimental imprecision and material heterogeneity, $E_{R M S}$ is calculated between the average experimental curve and each one of the four experimental curves. The variation of this error as a function of $h_{\max } / R$ for the four experimental tests is presented in Fig.10. From these errors, the maximal value of $E_{R M S}$ is considered for each value of $h_{\max } / R$. The average curve associated to the maximal value of $E_{R M S}$ leads to the characterization of a confidence domain that takes into account the experimental imprecision and the material heterogeneity. Therefore, since one point of the hardening law is identified for each penetration depth, the confidence domain described in section 2 is reduced to a minimum and a maximum values of stress for each $h_{\max } / R$. This way, the confidence domain is built up point by point. 
For each $\varepsilon_{a R}$, the maximum and the minimum values of stress are determined using the material parameter sets $\left(\sigma_{y}, n\right)$, corresponding to the points $\mathrm{b}$ and $\mathrm{d}$ of the isovalue ellipse represented Fig.7(a) as follow:

point $b$

$k=k_{0}-Y \sin \theta_{A R}$
$n=n_{0}+Y \cos \theta_{A R}$ point d

$$
\begin{aligned}
& k=k_{0}+Y \sin \theta_{A R} \\
& n=n_{0}-Y \cos \theta_{A R}
\end{aligned}
$$

The confidence domain built up from the average experimental $F-h$ curve is presented in Fig.11. All the hardening laws that are located inside the confidence domain lead to $F-h$ curves that give $E_{R M S}$ smaller than the maximal value of $E_{R M S}$ represented in Fig.10. Thus the confidence domain regroups all possible solutions taking into account the experimental imprecision and the material heterogeneity. The four F-h curves, presented in Fig.3, were used to characterize the material and the identified hardening laws are presented in Fig.11. It can be observed in this figure that the four hardening laws are located inside the confidence domain.

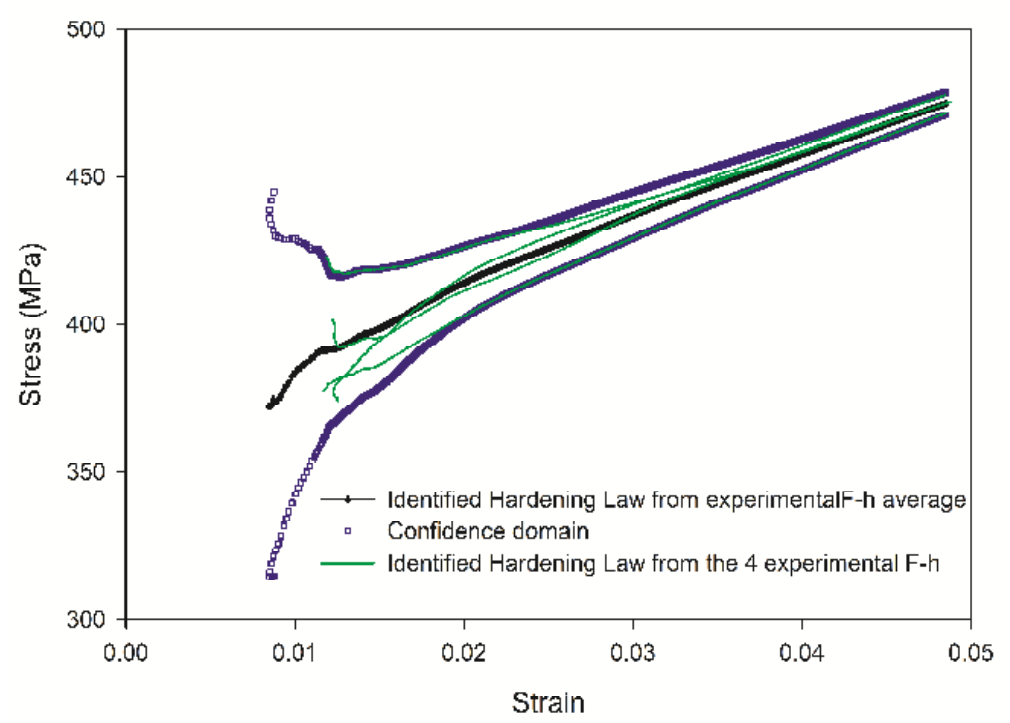

Fig.11: Confidence domain and the four identified hardening laws determined from each one of the experimental $F$ - $h$ curves 


\section{Discussion}

Fig.11 shows that the width of the confidence domain decreases with the increase in penetration depth. This result shows that the higher the penetration depth, the higher the precision of the identification from a $F$ - $h$ curve is. Six values of $h_{\max } / R$ are considered, see Fig.12. For these six values of $h_{\max } / R$, six values of $E_{R M S}$ corresponding to the maximal experimental errors are obtained (see Fig.10). Fig.12 shows the six isovalues of $E_{R M S}$ obtained in the diagram $\left[\sigma_{y}, n\right]$. It can be seen in this figure that the quasi ellipses corresponding to the isovalues of $E_{R M S}$ rotates with the variation in $h_{\max } / R$ value. The higher the value of $h_{\max } / R$, the higher the values of $\theta_{a r}$ and $\varepsilon_{a r}$ are.

The surface of each quasi ellipse decreases when $h_{\max } / R$ increases (Fig.12). This result confirms that because of the experimental imprecision, the smaller the penetration depth, the smaller the precision of the identified results is.

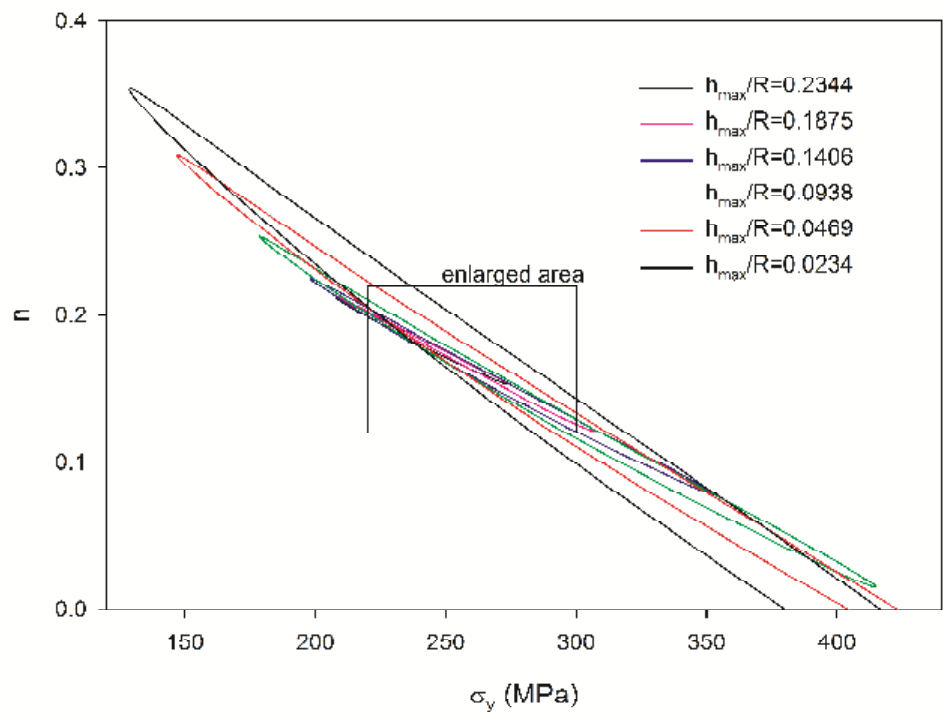

(a) 


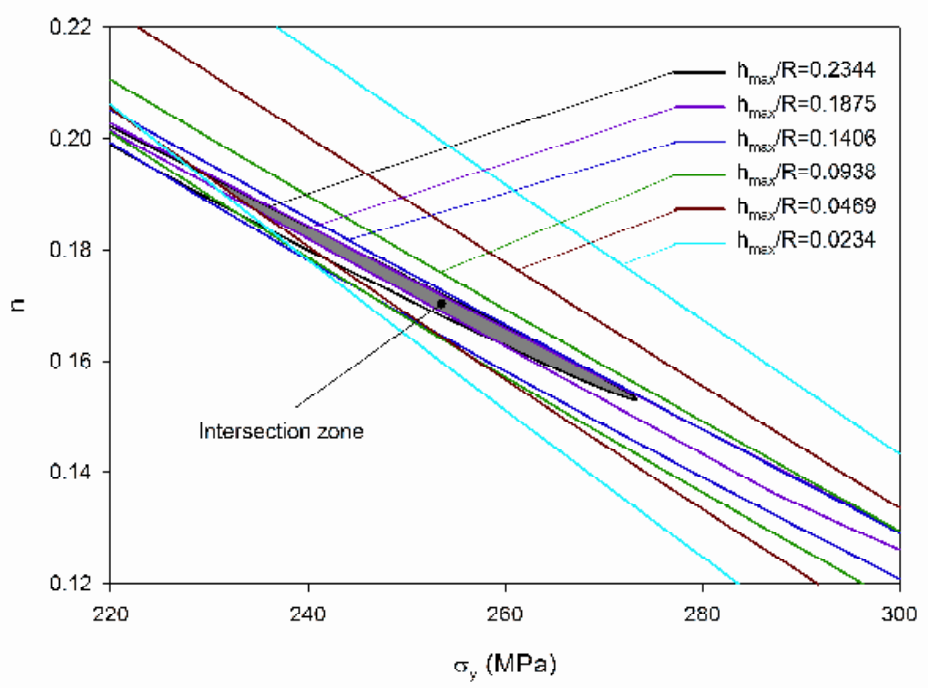

(b)

Fig.12: Quasi ellipses corresponding to the isovalues of the considered penetration depths (a) total domain (b) enlarged area around the intersection zone

The surface corresponding to the intersection zone of the quasi ellipses obtained for different values of $h_{\max } / R$ (Fig.12(b)) should be considered for the identification of the Hollomon law of the material. For all these values of $h_{\max } / R$, the material parameter sets located inside the intersection zone lead to $F$ - $h$ curves that give $E_{R M S}$ smaller than the maximal value of the experimental error.

The results presented in section 3 illustrate the problem of the uniqueness of the solution and the influence of the choice of penetration depth. The proposed method allows identifying the hardening law of the material for specific values of strain taking into account experimental imprecision and material heterogeneity.

The influence of the choice of the error ( $E_{R M S}$ in our case) is studied in the following section.

\section{4- Influence of the choice of error}

The procedure proposed above is applied to obtain the hardening law of the 20MnB5 steel using a different definition of error. This error is defined with the following equation: 
$R E_{R M S}\left(h_{\max } / R\right)=100 \times \sqrt{\frac{1}{h_{\max }} \int_{0}^{h_{\max }}\left(\frac{F_{1}-F_{2}}{F_{1}}\right)^{2} d h}$

where $R E_{R M S}$ is the root mean square relative error expressed in percentage.

$E_{R M S}$ and $R E_{R M S}$ do not depend on the number and on the distribution of the points of the experimental $F$ - $h$ curves. Contrary to $E_{R M S}, R E_{R M S}$ is defined so that the value of the error is equally influenced by small and high values of load. Since the proposed average representative strain is determined from the distribution of the error between an experimental curve and the $F-h$ curves of the database, the error definition has an influence on the determined average representative strain (Fig.13).

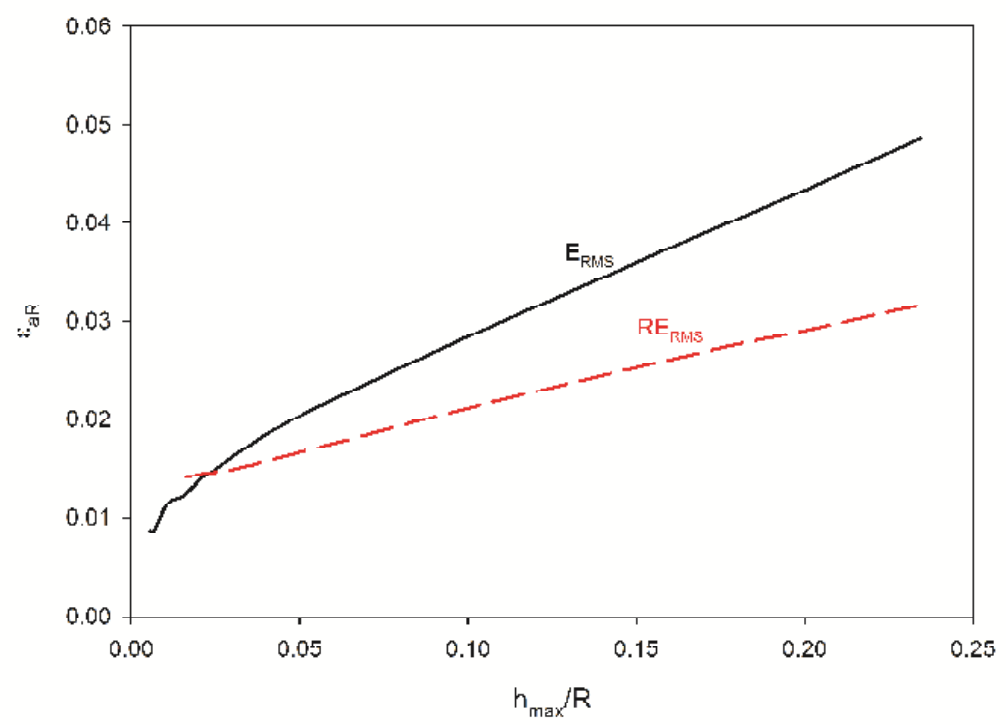

Fig.13: Comparison between the variation of the average representative strains determined with $E_{R M S}$ and $R E_{R M S}$ as a function of $\boldsymbol{h}_{\max } / R$

Moreover, the identified Hollomon hardening law parameter sets depend on the choice of the error. For example, for $h_{\max } / R=0.2344$, the identified Hollomon hardening law parameter set, $\sigma_{y}=264 \mathrm{MPa}$ and $n=0.161$, obtained from $R E_{R M S}$ is different from that calculated using $E_{R M S}$, i.e. $\sigma_{y}=240 \mathrm{MPa}$ and $n=0.182$. 
Using the sets $\left(\varepsilon_{a r}, \sigma_{a r}\right)$ determined with $R E_{R M S}$ for various $h_{\max } / R$, the hardening law of the material is built up point by point (Fig.14). Despite the differences observed between the identified Hollomon hardening law parameter sets $\left(\sigma_{y}, n\right)$ obtained from $R E_{R M S}$ and $E_{R M S}$, Fig.14 shows that the built up hardening law superimposes the tensile test curves. This result confirms that the average representative strain indicates perfectly the part of the hardening law that is identified when using a $F-h$ indentation curve. With the proposed procedure, the error formula only influences the range of strain in which the hardening law is identified.

The comparison between Fig.9 and 14 shows that the width of the confidence domain obtained with $R E_{R M S}$ is higher than the one obtained with $E_{R M S}$. Hence, $E_{R M S}$ leads to better precision than $R E_{R M S}$.

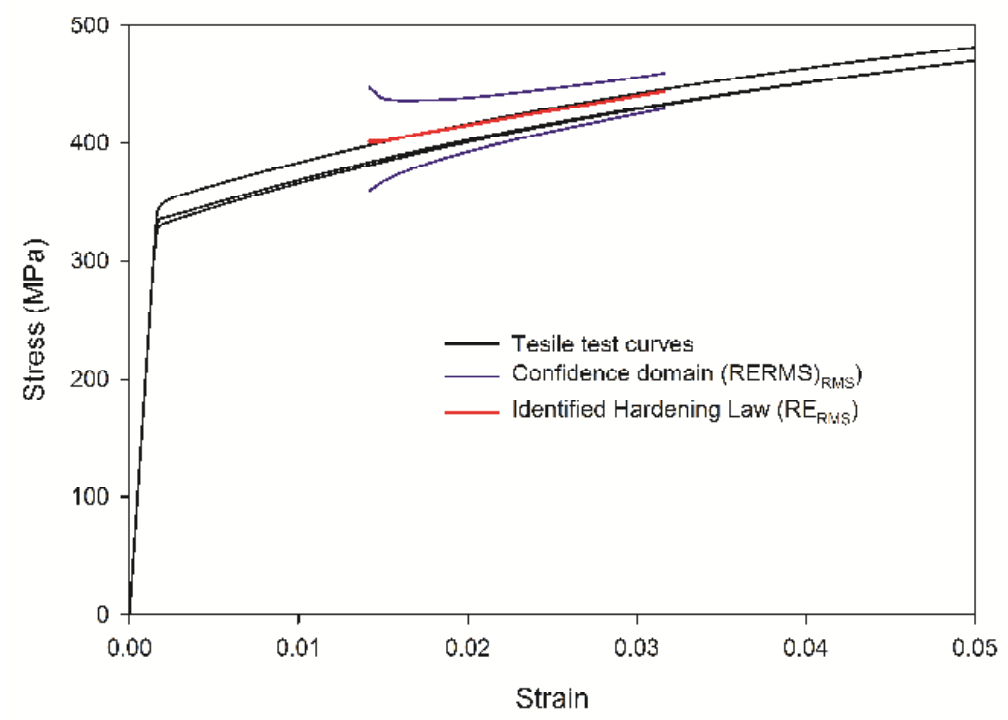

Fig.14: Tensile test curves, hardening law identified with the proposed method using $R E_{R M S}$ and confidence domain determined with the proposed method using $R E_{R M S}$.

\section{Discussion}


As previously mentioned, the points of the experimental $F-h$ curve have not the same influence on the identified results when $R E_{R M S}$ and $E_{R M S}$ are used. The influence of the error formula on the values of the plastic properties of materials extracted from the spherical indentation loading curve was expected since $h_{\max } / R$ has an influence on these values. This influence was never studied in previous works [11,12,16-22]. Moreover, neither the error formula used to obtain the analytical expressions of the $F-h$ curve as a function of material properties, nor the error formula used to evaluate the hardening law from this analytical expressions were given in these works. We show in this study that the influence of the error formula and the value of $h_{\max } / R$ should be considered when we use methods to evaluate the stress-strain curve from the $F-h$ indentation curve.

\section{4- Conclusion}

In this study, a new method to extract the hardening law of materials from an instrumented spherical indentation loading curve is proposed. The results obtained with this method are very satisfactory when compared to the tensile test curves. Using the proposed average representative strain, this method takes into account multiple difficulties that were not specified in the literature:

- Depending on the value of the penetration depth, various Hollomon hardening law parameter sets $\left(\sigma_{y}, n\right)$ can be identified from a single $F$ - $h$ spherical indentation curve. The proposed method allows considering all these parameter sets. Each penetration depth is considered to identify one point of the hardening law.

- The extraction of a stress-strain curve of a material from an indentation test only give precise result for a range of strain. This range of strain is obtained with the proposed method. 
- It is impossible to obtain two or more perfectly similar experimental indentation curves. Using the average experimental curve and the maximal experimental error, the proposed method allows identifying a confidence domain which takes into account the experimental imprecision and the material heterogeneity.

- Different Hollomon hardening law parameter sets $\left(\sigma_{y}, n\right)$ are obtained when different error formula are used to calculate the gap between indentation curves. With the proposed procedure, the identified stress-strain curve does not depend on the error formula. The choice of the error only influences the range of strain in which the hardening law is identified and the width of the confidence domain.

\section{References}

[1] R.R. Ambriz, D. Chicot, N. Benseddiq, G. Mesmacque, S.D. de la Torre, Eur. J. Mech. ASolids 30 (2011) 307.

[2] N.A. Branch, N.K. Arakere, G. Subhash, M.A. Klecka, Int. J. Plast. 27 (2011) 728.

[3] K.-H. Chung, W. Lee, J.H. Kim, C. Kim, S.H. Park, D. Kwon, K. Chung, Int. J. Solids Struct. 46 (2009) 344.

[4] G. Das, M. Das, S. Sinha, K.K. Gupta, S. Chakrabarty, A.K. Ray, Mater. Sci. Eng. A 513-514 (2009) 389.

[5] L.M. Farrissey, P.E. McHugh, Meas. Interpret. InternalResidual Stress. 399 (2005) 254.

[6] C. Moussa, O. Bartier, G. Mauvoisin, P. Pilvin, G. Delattre, J. Mater. Res. 27 (2012) 20.

[7] A. Nayebi, R. El Abdi, O. Bartier, G. Mauvoisin, M. Buisson, J. Mater. Process. Technol. 141 (2003) 276.

[8] K. Tunvisut, E.P. Busso, N.P. O’dowd, H.P. Brantner, Philos. Mag. A 82 (2002) 2013.

[9] M. Zhao, Y. Xiang, J. Xu, N. Ogasawara, N. Chiba, X. Chen, Thin Solid Films 516 (2008) 7571.

[10] J.-H. Ahn, D. Kwon, J. Mater. Res. Vol. 16 (2001) 3170.

[11] Y. Cao, X. Qian, N. Huber, Mater. Sci. Eng. A 454-455 (2007) 1.

[12] Y.P. Cao, J. Lu, Acta Mater. 52 (2004) 4023.

[13] J.S. Field, M.V. Swain, J. Mater. Res. Vol. 10 (1995) 101.

[14] E. Jeon, J.-Y. Kim, M.-K. Baik, S.-H. Kim, J.-S. Park, D. Kwon, Mater. Sci. Eng. A 419 (2006) 196.

[15] J.-Y. Kim, K.-W. Lee, J.-S. Lee, D. Kwon, Proc. 33rd Int. Conf. Metall. Coat. Thin Films ICMCTF 2006 33rd Int. Conf. Metall. Coat. Thin Films 201 (2006) 4278. 
[16] H. Lee, J. Haeng Lee, G.M. Pharr, J. Mech. Phys. Solids 53 (2005) 2037.

[17] J.H. Lee, T. Kim, H. Lee, Int. J. Solids Struct. 47 (2010) 647.

[18] N. Ogasawara, N. Chiba, X. Chen, Mech. Mater. 41 (2009) 1025.

[19] B. Taljat, T. Zacharia, F. Kosel, Int. J. Solids Struct. 35 (1998) 4411.

[20] M. Zhao, N. Ogasawara, N. Chiba, X. Chen, Acta Mater. 54 (2006) 23.

[21] N. Ogasawara, N. Chiba, X. Chen, J. Mater. Res. (2005) 2225.

[22] X. Chen, N. Ogasawara, M. Zhao, N. Chiba, J. Mech. Phys. Solids 55 (2007) 1618.

[23] H. Lan, T.A. Venkatesh, Philos. Mag. 87 (2007) 4671.

[24] Y.-T. Cheng, C.-M. Cheng, Mater. Sci. Eng. R Rep. 44 (2004) 91.

[25] H. Lan, T.A. Venkatesh, J. Mater. Res. Vol. 22 (2007) 1043.

[26] C. Moussa, X. Hernot, O. Bartier, G. Delattre, G. Mauvoisin, J. Mater. Sci. 49 (2014) 592.

[27] Y.-C. Kim, S.-K. Kang, J.-Y. Kim, D. Kwon, J. Mater. Sci. 48 (2013) 232.

[28] O. Bartier, X. Hernot, G. Mauvoisin, C. Moussa, Matér. Tech. 101 (2013). 